\title{
RENTAS DE LOS OBISPOS ESPAÑOLES Y PENSIONES QUE LAS GRAVAN EN EL ANTIGUO RÉGIMEN (1556-1834)
}

\author{
MaXimiliano Barrio Gozalo \\ Universidad de Valladolid
}

Fecha de recepción: diciembre 2013

Fecha de aceptación: abril 2014

Aunque todavía hoy resulta difícil evaluar con cierta verosimilitud la riqueza que la Iglesia española poseía durante el antiguo régimen por la falta de estudios monográficos sobre muchas diócesis, los datos disponibles permiten afirmar que se fue incrementando a lo largo de los siglos modernos, de forma que si a principios del seiscientos apenas suma el diez por ciento del producto nacional bruto, un siglo y medio después sube hasta el catorce por ciento ${ }^{1}$. Este volumen de riqueza se distribuye de forma desigual entre los distintos beneficiarios, pero son los obispos los que acaparan el que porcentaje relativamente más elevado. Teniendo esto presente, en las páginas siguientes analizo de forma sintética las rentas episcopales, para centrarme después en el estudio de las pensiones que las gravan, y terminar con unas páginas sobre la inversión de la renta disponible por los obispos ${ }^{2}$

\footnotetext{
1. Barrio Gozalo, M.: «The Landed Property of the Spanisch Church during the Ancien Regime», The journal of European economic history, 31/2 (2002), pp. 245-272; y BERNAL, A.M. y. LóPEZ MARTín, A.L.: «Las rentas de la Iglesia en el Antiguo Régimen», en Iglesia, Sociedad y Estado en España, Francia e Italia (ss. XVIII al XX), Alicante, Instituto Gil-Albert, 1992, pp. 15-40.

2. Prescindiendo de los estudios de carácter diocesano que han aparecido en los últimos años, remito a la visión global que ofrece Barrio Gozalo, M.: El Real Patronato y los obispos españoles del Antiguo Régimen (1556-1834), Madrid, Centro de Estudios Políticos y Constitucionales, 2004, pp. 251-286; y de forma más sintética en «La economía de los obispos en la España del Antiguo Régimen», en Fra spazio e tempo. Studi in onore di Luigi De Rosa, a cura di I. Zilli, Napoli, Edizioni Scientifiche Italiane, 1995, vol. I, pp. 33-57.
} 


\section{LAS RENTAS EPISCOPALES}

Entre las fuentes que permiten conocer las rentas episcopales destacan las Relaciones de valores de las mitras enviadas a las Secretarías del Real Patronato de Castilla y de Aragón, que abarcan desde mediados del siglo XVI hasta 1834 y se encuentran en los archivos de la Corona de Aragón de Barcelona, General de Simancas e Histórico Nacional de Madrid. Cuando moría un obispo o renunciaba a la sede, la Secretaría escribía al cabildo catedral pidiéndole relación detallada de las rentas del obispo en el trienio o quinquenio anterior con el fin de cargar al nuevamente provisto la pensión de la tercera o cuarta parte sobre el importe de la renta líquida y deducir la mesada que tenía que pagar al rey. El contador del cabildo elaboraba las cuentas, analizando año por año o de forma global, y las enviaba a la Secretaría, donde eran supervisadas por la contaduría, que las daba por buenas o las ponía reparos, a los que debía dar satisfacción el autor de las mismas ${ }^{3}$.

Estas relaciones son muy útiles para nuestro objetivo porque cuando las rentas se administran por cuenta del obispo, junto con la cuantía de los frutos indican normalmente los precios a que se venden y su importe. Sin embargo, presentan el inconveniente de que, en vez de valorar los productos al precio real de venta, lo hacen al de la tasa cuando aquél era superior. Esta práctica, seguida de forma generalizada por los obispos hasta finales del setecientos, da lugar a que las cifras que ofrecen sean frecuentemente más bajas que lo que importa la renta real de la mitra, fenómeno que hay que tener en cuenta a la hora de interpretar sus datos.

Las rentas de los obispos estaban constituidas por tres sumando principales: rentas cobradas en cuanto titulares del dominio eminente de propiedades rústicas, urbanas e industriales; frutos decimales que perciben en distintas parroquias de la diócesis, y rentas de carácter vario que disfrutan en concepto de réditos de censos y juros, derechos señoriales, de curia y escribanías. Tres capítulos que, aunque en teoría aparecen perfectamente diferenciados, en la práctica resulta difícil individualizar. Por ello me limito a señalar los factores comunes que inciden en la fluctuación de cada concepto y la parte que cada uno aporta a la renta episcopal ${ }^{4}$.

En primer lugar, el importante patrimonio rústico de las mesas episcopales tiene su origen en el medievo y es consecuencia de las donaciones que los reyes y nobles hicieron a los prelados después de la reconquista del territorio y restauración de las sedes episcopales, y en menor medida de otras personas particulares y de compras. El resultado de este proceso de acumulación se tradujo en la formación de importantes patrimonios de carácter rústico, que en algunos casos adquieren especial significación, como sucede en los obispados gallegos, catalanes y Toledo, cuyo titular detenta la

\footnotetext{
3. Estas relaciones se encuentran en el Archivo de la Corona de Aragón (= ACA), Consejo de Aragón, legs. 122-131, 547-550 y 574; Archivo General de Simancas (=AGS), Patronato Eclesiástico, legs. 135-137; y Archivo Histórico Nacional (= AHN), Consejos, legs. 16978-17064, 18872-19365 y 19983-19993.

4. Barrio Gozalo, M.: El Real Patrimonio y los obispos españoles..., pp. 257-265.
} 
propiedad de más de siete mil hectáreas de tierra ${ }^{5}$. En cambio otras mesas episcopales apenas tienen propiedades de este tipo, como sucede en el reino de Granada.

Si al producto de las propiedades rústicas, sumamos el de las urbanas e industriales (casas, molinos, mesones, etc.), que explotadas en régimen de alquiler o arrendamiento producen sustanciosas rentas, llegamos a la conclusión de que los obispos ingresan por este concepto una elevada cantidad de dinero, que en la segunda mitad del setecientos supera los dos millones y medio reales de vellón, lo que representa algo más del ocho por ciento de las rentas episcopales, que en Cataluña sube al catorce y en Galicia al treinta, aunque son muchas las diferencias que se observan de unas mitras a otras y las fluctuaciones que se producen a lo largo del periodo ${ }^{6}$.

En segundo lugar, los ingresos provenientes de los frutos decimales constituyen el sumando principal de las rentas episcopales, con la excepción de algunas gallegas y catalanas. Su cuantía, aunque varía sensiblemente de unas a otras y fluctúa al unísono de las cosechas y, sobre todo, de los precios de los productos agropecuarios, en la segunda mitad del setecientos representa más del ochenta por ciento de las rentas episcopales, aunque su aportación porcentual difiere mucho de unas a otras, e incluso en una misma mitra puede variar con el paso del tiempo. La cuantificación del acervo decimal que corresponde a los obispos es difícil de precisar por las diferentes formas de explotación que utilizan, aunque los datos de los años 1756-1773 pueden servir de orientación. Los diezmos de granos y menudos que perciben los prelados de Castilla superan anualmente el medio millón de fanegas de grano y los cinco millones de reales, en concepto de diezmos arrendados y de los menudos de corderos, lana, azafrán, aceite, vino y otras menudencias ${ }^{7}$. En líneas generales su evolución camina prácticamente al unísono de la producción y, por tanto, experimenta un descenso importante desde los últimos años del siglo XVI hasta la segunda mitad del XVII, en que se inicia un largo periodo de expansión que no remite hasta finales del XVIII ${ }^{8}$. Este cuantioso acervo se destina en su mayor parte a la venta y su importe está sujeto a las fluctuaciones de las cosechas y de los precios.

En tercer lugar, los obispos perciben otros ingresos de carácter vario e inferior cuantía, como son los intereses de juros y censos, derechos señoriales, curias y escribanías, sello, luctuosas, raciones canonicales, penas de cámara y otras menudencias de escasa cuantía, cuyo importe relativo va descendiendo progresivamente y en la segunda mitad del setecientos apenas aporta el cinco por ciento de las rentas episcopales. Pero este descenso se vio compensado con el mayor peso que adquirió el derecho de

5. Donezar, J.M.: Riqueza y propiedad en la Castilla del Antiguo Régimen. La provincia de Toledo en el siglo XVIII, Madrid, Instituto de Estudios Agrarios, 1984, pp. 326-327.

6. Las monedas que se utilizan son el real de vellón, de 34 maravedíes, y el ducado castellano de 11 reales.

7. AHN, Consejos, leg. 4181. La fanega castellana tiene una capacidad de 55 litros y medio.

8. Anes Álvarez, G.: Las crisis agrarias en la España Moderna, Madrid, Taurus, 1970; y «Tendencias de la producción agrícola en tierras de la Corona de Castilla (siglos XVI al XIX)», Hacienda Pública Española, 55 (1978), pp. 97-111; MARcos Martín, A.: España en los siglos XVI, XVII y XVIII. Economía y sociedad, Barcelona, Crítica, 2000, pp. 350-356, 474-492 y 584-623. 
cops en la mitra de Barcelona ${ }^{9}$ y los votos que cobraban los obispos de Mondoñedo, Orense y Santiago ${ }^{10}$; de tal manera que en la segunda mitad del setecientos el importe de este conjunto de ingresos se acerca a los tres millones de reales y representa casi el nueve por ciento las rentas episcopales, aunque en las mitras catalanas sube al diecinueve y en las gallegas supera el cincuenta por ciento.

La importancia de los sumandos que conforman las rentas episcopales difiere de unas mitras a otras y también con el paso del tiempo. Por ello, como algo referencial y agrupando las mitras por regiones, se puede afirmar que el predominio de los diezmos es absoluto, pues aportan más del ochenta por ciento de las rentas episcopales, mientras que las propiedades y los otros ingresos proporcionan el resto. Sólo en las mitras gallegas y en algunas catalanas los diezmos pierden la primacía.

Los obispos, ante las distintas posibilidades de explotar sus rentas, utilizan por lo general dos regímenes, a veces simultáneos: el arriendo y la administración directa. En las propiedades, ya sean tierras o fincas urbanas, se practica la cesión del dominio útil a los concejos y campesinos por largos periodos de tiempo o a perpetuidad a través de escrituras de foro o censo enfitéutico, y también el arrendamiento por cortos periodos de tiempo. La entrega del dominio útil de la tierra, aunque fue perdiendo importancia con el paso del tiempo frente a otras formas contractuales más ágiles, como el arrendamiento por periodos de tres a ocho años, en el caso de los obispos con mayor patrimonio rústico, como los gallegos, catalanes y aragoneses, se mantuvo casi invariable. Esto dio lugar a que las rentas provenientes de las heredades arrendadas fueran las más fluctuantes, al estar sometidas a revisión cuando se renovaban los contratos, mientras que las dadas a foro o censo parece que con el paso del tiempo alcanzaron una estabilidad favorable al campesino, máxime si se pagaban en dinero.

En las rentas de carácter decimal unos obispos utilizan el sistema de arrendamiento de todos o parte de los diezmos y otros los administran. Sin embargo, desde finales del siglo XVIII la mayoría de los prelados optó por la administración directa de los diezmos de granos, sin duda para beneficiarse del alza que experimentan los precios y quizá también para cumplir la real orden de 1798, en la que se recomendaba a los prelados que administrasen ellos mismos los diezmos, pues «no es de creer que los dejasen de vender en los tiempos en que más lo necesita el pueblo, reservándolos con el torpe deseo de aumentar su precio» ${ }^{11}$. No obstante, son tantas las excepciones y tan variadas que para hablar con precisión habría que analizar el sistema que utilizaba cada obispo de forma preferencial, al menos en las rentas decimales, pues en los bienes raíces era más similar.

9. El obispo recibe la mitad del derecho de cops, que se paga por el trigo foráneo que se vende en el mercado público de la ciudad, y su importe pasa de los quince mil reales que produce hasta mediados del setecientos a medio millón en la última década del siglo.

10. Rey Castelao, O,: «El voto de Santiago en Galicia: regímenes contributivos e interpretaciones de sus series», Compostelanum, 33 (1988), pp. 385-468.

11. AHN, Consejos, leg. 17046. Real orden comunicada a los arzobispos y obispos, cabildos y demás prelados eclesiásticos del reino. Madrid 23 junio 1798. 
Los quince millones de reales que importan las rentas episcopales en el último tercio del siglo XVI permanecen estancados a lo largo del XVII y primera mitad del XVIII, pero luego, en la segunda mitad del XVIII y primer tercio del XIX, los ingresos se duplican ampliamente respecto a los habidos dos siglos antes, aunque las diferencias regionales son muchas. Las rentas episcopales de la Corona de Aragón tienen un comportamiento bastante lineal $\mathrm{y}$, de forma paulatina, se van incrementando hasta triplicar su importe a finales del setecientos, sin que se aprecie una caída generalizada en el primer tercio del ochocientos. En cambio, en Castilla se produce un estancamiento de hecho entre finales del quinientos y mediados del setecientos, que en las diócesis del interior se convierte en retroceso y en las de la periferia en ligero aumento; en la segunda mitad del setecientos las rentas duplican su valor a consecuencia del aumento de los precios, que tienen una subida similar, pero en el primer tercio del ochocientos se produce un descenso, que se acentúa a partir de 1820 por la conjunción de la bajada de los precios agrícolas y la generalización de la mala forma de diezmar.

Cuadro 1. Importe de la renta bruta de los obispos (Media anual en reales de vellón)

\begin{tabular}{|l|r|r|r|r|r|r|}
\hline \multirow{2}{*}{ Región } & \multicolumn{2}{|c|}{$\begin{array}{c}\text { 1566-1599 } \\
\text { Reales Índice }\end{array}$} & \multicolumn{2}{c|}{$\begin{array}{c}\text { 1600-1749 } \\
\text { Reales Índice }\end{array}$} & \multicolumn{2}{c|}{$\begin{array}{c}\text { 1750-1834 } \\
\text { Reales Índice }\end{array}$} \\
\hline Corona de Aragón: & 2.936 .185 & 100,0 & 3.516 .439 & 119,8 & 9.107 .719 & 310,2 \\
- Aragón & 1.136 .490 & 100,0 & 1.188 .510 & 104,6 & 2.230 .398 & 196,3 \\
- Cataluña & 754.651 & 100,0 & 1.061 .779 & 140,7 & 2.609 .095 & 354,7 \\
- Mallorca & 148.425 & 100,0 & 226.052 & 152,3 & 643.321 & 433,4 \\
- Valencia & 896.619 & 100,0 & 1.040 .098 & 116,0 & 3.624 .914 & 404,3 \\
\hline Corona de Castilla: & 12.231 .569 & 100,0 & 12.410 .872 & 101,5 & 23.630 .633 & 193,2 \\
- Andalucía & 2.867 .272 & 100,0 & 3.250 .163 & 113,3 & 6.340 .469 & 221,1 \\
- Canarias & 168.375 & 100,0 & 275.230 & 163,5 & 507.292 & 301,3 \\
- Castilla la Nueva & 3.772 .244 & 100,0 & 3.617 .462 & 95,9 & 6.801 .430 & 180,3 \\
- Castilla la Vieja y León & 2.914 .275 & 100,0 & 2.670 .096 & 91,6 & 4.856 .222 & 166,6 \\
- Extremadura & 954.128 & 100,0 & 903.637 & 94,7 & 1.473 .334 & 154,4 \\
- Galicia & 901.283 & 100,0 & 975.953 & 108,3 & 2.378 .212 & 263,9 \\
- Murcia & 226.718 & 100,0 & 316.624 & 139,6 & 683.235 & 301,4 \\
- Navarra & 427.274 & 100,0 & 401.707 & 94,0 & 590.439 & 138,2 \\
\hline España & 15.167 .754 & 100,0 & 15.927 .311 & 105,0 & 32.738 .352 & 215,8 \\
\hline
\end{tabular}

Ahora bien, para la mejor compresión de los datos del cuadro hay que tener en cuenta que las rentas de los obispos, al provenir en más del ochenta por ciento de frutos decimales, estaban sujetas a las fluctuaciones de las cosechas y de los precios, de tal manera que la conjunción de ambas variables determina el movimiento de los ingresos. Por esta razón, hasta finales del setecientos, cuando los granos se administran por cuenta del prelado, el movimiento de la renta viene determinado básicamente por la fluctuación de los productos, porque los granos se valoran al precio de la tasa; pero a partir de esta fecha son los precios los que determinan el movimiento de las rentas porque los granos se valoran al precio de venta. En cambio, cuando se arriendan el precio actúa siempre como factor determinante. Por lo demás, el movimiento de los ingresos 
se atiene en buena medida a la evolución de la producción agraria del antiguo régimen, sin olvidar las contingencias políticas, geográficas y coyunturales.

Aunque la cronología de la producción agraria tiene unos matices propios en cada región, se puede afirmar que la segunda mitad del siglo XVI se encuadra dentro de una fase de expansión de la producción agrícola y de las rentas agrarias, que hace posible el aumento de las rentas episcopales hasta los últimos años del siglo, en que se produce un cambio de tendencia y las rentas de algunos obispados de la España interior comienzan a bajar. En las dos Castillas y León el cambio de tendencia se produce en torno a 1580, al igual que sucede en Extremadura y en buena parte de Galicia, mientras que en el reino de Granada acaece después de la rebelión de las Alpujarras (1568-1570). En Aragón y Valencia la expansión se frena en torno a 1575, en que se inicia una fase de estancamiento que se prolonga hasta la expulsión de los moriscos; en cambio, en Cataluña, Mallorca y Canarias la expansión continúa.

Al finalizar el siglo las rentas de la mayor parte de los obispos gallegos y castellano-leoneses experimenta un descenso importante. Las de Lugo, Orense, Santiago (sólo las que cobra en Galicia) y Tuy bajan casi un 20 por 100 respecto al nivel de 1575-1585, en cambio las de Mondoñedo permanecen estables durante el último tercio del siglo ${ }^{12}$. Las de Ciudad Rodrigo disminuyen un 25 por 100 en la última década y el obispo lo justifica porque «desde el año 1595 hasta el presente (1601) han bajado mucho las rentas de pan y dinero de las yerbas, por haberse vendido a particulares los pastos y tierras concejiles» ${ }^{13}$. En León caen un 23 por 100 y en 1600 importan un 39 por 100 menos que en 1589 «a causa de las hambres, peste rigurosa y nieves que consumieron a la gente y al ganado» ${ }^{14}$. Algo similar ocurre en Zamora, aunque la quiebra se acentúa en los años 1598-1600:

«El primero de los tres fue de mucha hambre, y así todo el pan que yo tuve, sin vender una fanega, se dio a los pobres y gasto de mi casa, porque hubo día de mil pobres a la limosna de la puerta, y no me valió aquel año, quitando pensiones, subsidio y excusado, cinco mil ducados, y di de limosna más de ocho mil. El segundo hubo peste, que fue necesario acudir con lo que tuvimos, y por falta de gente bajaron los arrendamientos y se cogieron menos frutos. Y el tercero, aunque hubo algunos frutos de pan, no hay salida de ellos» ${ }^{15}$.

En otras diócesis, como Burgos, Osma y Segovia, la caída apenas se nota hasta después de 1600. En Castilla la Nueva y Extremadura las rentas episcopales continúan estabilizadas en los altos niveles alcanzados a finales del 1580, como sucede en Coria y Plasencia, o siguen subiendo: en Badajoz el alza de la última década respecto a la anterior es del veinte por ciento y en Cuenca y Sigüenza de casi un diez ${ }^{16}$. En los dos archipiélagos también hay que tener en cuenta la situación geopolítica, pues los ata-

12. AGS, Patronato Eclesiástico, legs. 136 (Santiago) y 137 (Lugo, Mondoñedo, Orense y Tuy).

13. Ibíd., leg. 136. Obispo de Ciudad Rodrigo a Cámara. Ciudad Rodrigo 18 mayo 1601.

14. Ibíd., leg. 136. Obispo de León a Cámara. León 21 diciembre 1601.

15. Ibíd., leg. 135. Obispo de Zamora a Cámara. Zamora 20 marzo 1601.

16. Ibíd., legs. 135 (Coria), 136 (Badajoz y Sigüenza) y 137 (Cuenca y Plasencia). 
ques corsarios o las guerras podían incidir negativamente y agravar la situación económica. El año 1593 la isla de Fuerteventura fue saqueada por los moros y hubo langosta, con lo cual el obispo no recogió ninguna renta y, además, tuvo que dar limosna a los vecinos para que pudieran comer y sembrar ${ }^{17}$.

En el siglo XVII se produce una contracción agraria que afecta sobremanera a las regiones de España interior y provoca el descenso de las rentas episcopales de ambas Castillas y Extremadura, que no consiguen recuperar los niveles alcanzados en el último tercio del siglo XVI hasta mediados del XVIII. En Castilla la Vieja y León la incidencia de la crisis fue muy aguda, y en la primera mitad del seiscientos las rentas episcopales descienden casi la cuarta parte. En Castilla la Nueva y Extremadura la caída no fue tan grande, pero se acentuó a partir de 1630, lo que explica que las rentas sean más altas en el primer tercio del siglo que en el segundo, pues el alza de los precios no pudo contrarrestar la disminución de la producción ${ }^{18}$. La guerra de Secesión de Portugal causó la ruina y despoblación de muchos lugares del obispado de Badajoz, e hizo que las rentas episcopales bajasen un sesenta por ciento en 1640-1666 respecto al nivel de 1600-1639. Su incidencia fue mucho menor en Coria y Plasencia, donde sólo descendieron un quince por ciento $^{19}$.

En las diócesis del reino de Valencia la expulsión de los moriscos produjo una caída de las rentas superior al veinte por ciento. Según indica el Consejo de Aragón en 1611 al proponer candidatos para ocupar la mitra valenciana, «el valor de sus rentas se ha visto reducido en más de veinte mil libras, estimándose su valor en cincuenta mil, sobre las que se puede cargar de quince a dieciséis mil libras de pensión, comprendiendo en ellas las antiguas, porque si bien no llega esta cantidad a la tercera parte del valor que al presente tiene la iglesia y éste ha de ir mejorando cada día al paso de cómo se vaya poblando el reino, tiene aquella dignidad algunas cargas forzosas y obligatorias a que acudir» ${ }^{20}$. Algo similar ocurrió en Orihuela y Segorbe. La peste de 1647 frenó la recuperación y hay que esperar a la segunda mitad del siglo para que se alcancen los niveles anteriores a la expulsión de los moriscos.

En Galicia las rentas episcopales experimentaron un pequeño retroceso en la primera mitad del siglo por el descenso de los votos que el arzobispo de Santiago cobraba en ambas Castillas y Andalucía, que aportaban casi las dos terceras partes de las rentas, y por la incidencia que la guerra de Portugal tuvo en Orense y en Tuy, lo que hizo bajar las rentas episcopales, que se mantuvieron en ese bajo nivel durante un cuarto de siglo.

En las demás regiones las rentas permanecen estancadas en los niveles que alcanzaron a finales del siglo XVI, como sucede en Andalucía, Aragón y Navarra, o con-

17. Ibíd., leg. 136.

18. De acuerdo con los datos que ofrecen López-SALAZAR, J. y MARTín GALÁN, M.: «La producción cerealista en el arzobispado de Toledo, 1463-1699», Historia Moderna y Contemporánea, 2 (1981), pp. 64-101, los diezmos de pan descienden un $16 \%$ entre 1600 y 1649.

19. Barrio Gozalo, M.: «Perfil socio-económico de una elite de poder, IV. Los obispos de Castilla la Nueva y Extremadura (1600-1840)», Antológica Annua, 33 (1986), pp. 257-258.

20. AHN, Consejos, leg. 19400. La libra valenciana equivale a 15 reales de vellón. 
tinuaron creciendo, como sucede en Cataluña, Mallorca y Canarias. Las rentas de los obispos catalanes tienen una línea ascendente hasta la revuelta de 1640-1653, que provocó un descenso del diez por ciento ${ }^{21}$, y el obispo de Tortosa lo explica con estas palabras:

«Antes de las guerras, que por nuestros pecados oprimieron tanto esta provincia, como estaban sus poblaciones enteras y con los moradores con ganados y posibilidad para la cultura de la tierra, valía este obispado en arriendo dieciséis o dieciocho mil libras, pero el año pasado de 1655, con ser uno de los que tuvieron más valor los frutos, como esta diócesis quedó reducida a suma pobreza con los sacos y violencias de los franceses, que la habitaron tantos años, y tan despoblada con los contagios de la peste que unos lugares están por la mayor parte arruinados, otros despoblados del todo y los mayores, que solían tener de cuatrocientos a quinientos vecinos, reducidos a la mitad, cuando más, dio tan gran baja la renta de la mitra que no valió más que 10.426 libras» ${ }^{22}$.

Mallorca tiene un comportamiento similar a Cataluña, aunque en la segunda mitad del siglo el aumento es más rápido. Algo parecido ocurre con las rentas del obispo de Canarias, que se incrementan a lo largo del siglo en consonancia con el comportamiento singular de la economía canaria ${ }^{23}$.

En la segunda mitad del siglo XVII se inicia un largo periodo de expansión de la producción que se prolonga hasta finales del XVIII, si bien el estancamiento continuó en muchos obispados hasta bien entrado el XVIII, acentuándose en los primeros años con motivo de la guerra de Sucesión, sobre todo en las diócesis fronterizas con Portugal. En Badajoz las rentas episcopales quedaron reducidas a la mitad de su valor «por haber talado el enemigo los campos y haciendas, y no bajar por este motivo la cabaña real, cuyo diezmo es el de mayor entidad de ella» ${ }^{24}$. Y lo mismo sucedió en Coria y Ciudad Rodrigo.

En el siglo XVIII asistimos a la expansión de la producción y al alza de los precios, aunque hay que esperar a la década de 1720 para que se empiece a apreciar el cambio de coyuntura, cuyos frutos se recogen en la segunda mitad del siglo, en que la conjunción de un ligero aumento de la producción con el alza desorbitada de los precios hizo subir la renta de los obispos a su nivel más alto, apreciándose en los últimos años del siglo unos valores «tan desorbitados que jamás se habían conocido ni se espera permanezcan ${ }^{25}$. Esto hace que en la última década las rentas de los obispos

21. ACA, Consejo de Aragón, leg. 550.

22. Ibíd., leg. 574. Obispo de Tortosa a Consejo de Aragón. Tortosa 28 agosto 1656.

23. Macias, A.M.: «Canarias y la crisis del siglo XVII. La singularidad isleña», Revista de Historia de Canarias, 176 (1992), pp. 179-206.

24. Archivio Segreto Vaticano (=ASV), Arch. Concist., Processus Consist., vol. 99, f. 455. Incluso el cabildo de Sigüenza afirma el 27 de junio de 1711 (AHN, Consejos, leg. 17051) que de los frutos de la mitra de 1710 no se podía hacer juicio «por lo mucho que consumieron y llevaron los soldados de unas y otras tropas, sacándoles de las cámaras».

25. Anes Alvarez, G.: «Las fluctuaciones de los precios del trigo, de la cebada y del aceite en España (17881808): Un contraste regional», en Economía e Ilustración en la España del siglo XVIII, Barcelona, Ariel, 1969, pp. 43-70. 
casi tripliquen su valor respecto a 1700-1724, siendo la subida mucho más acentuada en los obispados que administran los diezmos o el arriendo de los granos se paga en especie, que en los que siguen arrendándose a dinero. En el reino de Valencia la renta se multiplica por cuatro, en Castilla la Vieja y León casi por tres, en Castilla la Nueva, Extremadura y Cataluña por dos y medio, y en Andalucía y Aragón no llega a duplicarse.

En los primeros años del siglo XIX, a pesar de la disminución de los frutos decimales, como consecuencia de las crisis agrarias y de los efectos de la guerra de Independencia, los ingresos de los obispos se mantienen todavía altos y algunas mitras superan los de finales del XVIII, gracias a que los precios continúan siendo elevados y experimentan subidas espectaculares en los años de las crisis de subsistencia de 18031804 y 1811-1812. Pues, como dice el arzobispo de Granada al enjuiciar los valores de la mitra en el quinquenio 1810-1814, «aunque el menor pago de los diezmos es de la mayor consideración, los enormes precios de los granos, jamás conocidos e incapaces de subsistir variadas las cosas, han podido cubrir su antiguo esplendor ${ }^{26}$

Durante la guerra las rentas episcopales fueron secuestradas o sometidas a fuertes expolios. En diciembre de 1808 el mariscal Soult entró en la diócesis de Ávila y se apoderó de frutos de la mitra ${ }^{27}$; en Astorga el gobierno intruso secuestró las rentas en 1810 y así permanecieron hasta $1813^{28}$, al igual que sucedió en Calahorra, Pamplona, Toledo, Zamora y en otras más. En Ciudad Rodrigo, además del secuestro de las rentas, la guerra causó grandes destrozos en la economía y en la población del obispado. «La ganadería, que es su principal riqueza, sufre grandes pérdidas, sus dehesas están poco menos que desiertas, cuando antes se veían muy pobladas de ganados de toda especie, y la agricultura experimenta asimismo un conocido menoscabo, habiéndola privado de ganados de labor y brazos ${ }^{29}$. El obispo de Salamanca se vio privado de sus rentas durante los años $1808-1813$ por cesión a la regencia o secuestro del gobierno intruso, «sin haber dejado cosa alguna para el prelado, a causa de haber huido de su dominación, excepto algunas cantidades que con cautela sus administradores pudieron reservar ${ }^{30}$. Algo similar ocurrió en las demás diócesis, pues los secuestros, saqueos y pillajes de las tropas francesas, inglesas y de la guerrilla tuvieron igual importancia.

En algunas diócesis, los efectos de la guerra se agravaron con la negativa de algunos pueblos y muchos campesinos a pagar los diezmos, como indica el cabildo de Plasencia al explicar el descenso que tienen las rentas de la mitra en el quinquenio 1809-1813 respecto al de 1797-1801. «Los primeros años fueron quietos y pacíficos, y los segundos de invasión, temores y desconfianza; causa suficiente para que muchos

26. AHN, Consejos, leg. 17019. Arzobispo de Granada a Cámara. Granada 30 marzo 1815.

27. Ibíd., leg. 16981.

28. Ibíd., leg. 16979. Cabildo de Astorga a Cámara. Astorga 23 noviembre 1816.

29. Ibíd., leg. 17001. Obispo electo de Ciudad Rodrigo a Cámara. Madrid 22 diciembre 1814.

30. Ibíd., leg. 17039. Informe sobre la actuación del obispo de Salamanca durante la invasión francesa. Salamanca 21 junio 1815 
pueblos no pagasen los diezmos, señaladamente en la villa de Don Benito, que es la más rica del obispado, que contando con más de dos mil vecinos labradores apenas trescientos pagaron diezmo de granos y ganados, porque los labradores no sembraban tanto como antes y de lo poco que sembraban no se aprovechaban algunos por servir para las tropas, aun antes de la siega. Los ganados han disminuido, los valores de los pastos de las dehesas se han minorado por falta de pastores y todo ha tenido una considerable decadencia». Como resultado de estos sucesos las rentas de la mitra bajaron casi un cincuenta por ciento y la agricultura y ganadería, fundamentos de la riqueza del país, quedaron muy decaídas ${ }^{31}$

La restauración fernandina (1814-1820) no pudo frenar el naufragio de las mesas episcopales. Por el contrario, la generalización del mal modo de diezmar, el descenso de los precios de los productos agrarios y las medidas que se tomaron en materia de diezmos durante el Trienio Liberal (1820-1823), provocaron en los años 1824-1834 un descenso de más de la tercera parte respecto a los valores habidos en 1800-182032. En 1825 el cabildo de Murcia achaca el descenso de las rentas decimales a la poca religiosidad con que se pagaban, a causa de las malas doctrinas que se habían propagado y arraigado en la última época revolucionaria, y a la bajada que habían sufrido los precios agrarios, de tal manera que las rentas de la mitra habían disminuido más de la tercera parte de lo que importaban en el quinquenio 1815-181933. En los años sucesivos, con la abolición de la obligación civil de pagar los diezmos en $1837^{34}$ y el inicio de la desamortización, se consumó la ruina de las mesas episcopales.

La renta de los obispos estaba gravada con una serie de cargas y gastos fijos, como son los derivados de la administración, recolección de frutos, beneficio y cobranza de las rentas; de la presión fiscal, como el subsidio de galeras, el excusado (diezmos de la casa más rica de cada parroquia), los impuestos extraordinarios y otros conceptos de pequeña cuantía. Su importe se mueve entre el doce y el quince por ciento de la renta bruta y está condicionado por los conceptos incluidos y la cuantía de los mismos, pues no se debe olvidar que los costes de administración, parte mayoritaria de los gastos fijos, disminuyen sensiblemente cuando los obispos arriendan el todo o parte de sus rentas, ya que entonces desaparecen los gastos de portear y recoger los frutos. Por otra parte, el brusco aumento que se observa desde mediados del setecientos hay que

31. Ibíd., leg. 17035. Cabildo de Plasencia a Cámara. Plasencia 9 abril 1816.

32. Los descensos más altos se producen en Andalucía (65\%), Valencia (51\%), Castilla la Vieja y León (49 \%), Pamplona (46\%), Cataluña, Mallorca y Murcia (33\%), Castilla la Nueva y Extremadura (24\%), Galicia (18\%), etc.

33. AHN, Consejos, leg. 16997. Cabildo de Murcia a Cámara. Murcia 21 enero 1825.

34. Canales, E.: «Los diezmos en su etapa final», en La economía española al final del Antiguo Régimen, I. Agricultura, Madrid, Alianza, 1982, pp. 186-187, afirma que a la altura de 1837 las Cortes no tuvieron excesivos problemas para aprobar una ley de supresión del diezmo (Decreto de 29 de julio de 1837), pero no iba a ser tan fácil desprenderse de él. Junto a la ley que lo abolía se tuvo que promulgar su continuación durante un año y la dificultad de asegurar por otros medios las atenciones a que hacía frente el diezmo retrasó la solución definitiva hasta 1841, en que por fin se firmó el acta de defunción de un impuesto, que en muchas partes ya había muerto por agotamiento. 
achacarlo a la inclusión de algunos conceptos nuevos y, sobre todo, al incremento de los costes de administración, pues a partir del último tercio del siglo son muchos los obispos que optan por administrar directamente las rentas de granos para aprovecharse del alza de los precios. Fenómeno que se acusa más intensamente en los obispados de la Corona de Aragón, donde predominaba el sistema de arriendo y ahora algunos obispos optan por la administración directa.

Cuadro 2. Cargas y gastos fijos que gravan las rentas

(Media anual en reales de vellón)

\begin{tabular}{|c|c|c|c|c|c|c|c|c|c|}
\hline \multirow{2}{*}{ Periodo } & \multicolumn{3}{|c|}{ Corona de Aragón } & \multicolumn{3}{|c|}{ Corona de Castilla } & \multicolumn{3}{|c|}{ España } \\
\hline & Reales & Índice & $\%$ & Reales & Índice & $\%$ & Reales & Índice & $\%$ \\
\hline 1566-1599 & 311.486 & 100,0 & 10,6 & 1.494 .563 & 100,0 & 12,2 & 1.806 .049 & 100,0 & 11,9 \\
\hline $1600-1749$ & 458.545 & 147,2 & 13,0 & 1.673 .643 & 112,0 & 13,5 & 2.132 .188 & 118,1 & 13,4 \\
\hline $1750-1834$ & 1.395 .559 & 448,0 & 15,3 & 3.306 .419 & 221,2 & 14,0 & 4.701 .978 & 260,3 & 14,5 \\
\hline
\end{tabular}

Si el importe de las cargas y gastos fijos se descuenta de la renta bruta se obtiene la renta líquida, que se distribuye de forma desigual entre los obispos. Una simple mirada a los datos del cuadro tercero muestra las grandes diferencias existentes y pone de manifiesto, en primer lugar, que sólo once obispos (el 6,7 \% de los existentes) acaparan el 53 por 100 de las rentas, destacando los muy ricos de Toledo, Sevilla, Valencia y Santiago que acumulan un tercio de las rentas; en cambio los once más pobres sólo se benefician del cuatro por ciento. En segundo lugar, si nos fijamos en el rango económico que ocupan los obispos castellanos dentro del conjunto español vemos que en el periodo 1600-1749, sobre un total de cincuenta y cinco, dos se encuentran entre los más ricos, ocho entre los ricos, diecisiete entre los medianos y sólo siete entre los pobres; en cambio, en la Corona de Aragón sólo aparece Valencia entre los más ricos y Zaragoza entre los ricos, mientras que ocho son medianos y nueve pobres. En el periodo siguiente mejora sensiblemente la situación económica de los obispos, sobre todo en la Corona de Aragón, aunque Barbastro, Jaca y Solsona siguen sin llegar a los cien mil reales, junto con Ibiza y Menorca de nueva creación, al igual que sucede con Ceuta, Ciudad Rodrigo y Tudela en Castilla.

En líneas generales se puede afirmar que los obispados más ricos se sitúan en Castilla la Nueva, buena parte de Andalucía y Valencia, y Santiago de Compostela en Galicia y Zaragoza en Aragón; los medianos en Canarias, Castilla la Vieja y León, Extremadura, Mallorca, Navarra y sur de Cataluña, y los modestos y pobres en el resto de Aragón y Galicia, norte de Cataluña, Ibiza y Menorca. Por otra parte, el importe de su renta líquida y el rango económico que ocupan dentro del conjunto, ayuda a comprender el itinerario que, con carácter de cursus honorum, recorren los prelados en los sucesivos cambios de titularidad de sede $^{35}$.

35. Los obispados que no registran ninguna cantidad en alguna columna es porque todavía no se habían creado o no pertenecían a los reinos de España. Elna-Perpignan pasa a Francia en 1659; Ibiza se erige 
Cuadro 3. Importe de la renta líquida de los obispos (Media anual en reales de vellón)

\begin{tabular}{|c|c|c|c|c|c|c|}
\hline Obispado & \multicolumn{2}{|c|}{$\begin{array}{c}\text { 1566-1599 } \\
\text { Reales Rango }\end{array}$} & \multicolumn{2}{|c|}{$\begin{array}{c}1600-1749 \\
\text { Reales Rango }\end{array}$} & \multicolumn{2}{|c|}{$\begin{array}{c}\text { 1750-1834 } \\
\text { Reales Rango }\end{array}$} \\
\hline $\begin{array}{l}\text { Corona de Aragón: } \\
\text { - Albarracín } \\
\text { - Barbastro } \\
\text { - Barcelona } \\
\text { - Elna } \\
\text { - Gerona } \\
\text { - Huesca } \\
\text { - Ibiza } \\
\text { - Jaca } \\
\text { - Lérida } \\
\text { - Mallorca } \\
\text { - Menorca } \\
\text { - Orihuela } \\
\text { - Segorbe } \\
\text { - Solsona } \\
\text { - Tarazona } \\
\text { - Tarragona } \\
\text { - Teruel } \\
\text { - Tortosa } \\
\text { - Urgel } \\
\text { - Valencia } \\
\text { - Vic } \\
\text { - Zaragoza }\end{array}$ & $\begin{array}{r}2.624 .699 \\
98.795 \\
45.431 \\
81.759 \\
21.681 \\
80.658 \\
71.628 \\
- \\
38.035 \\
95.579 \\
137.775 \\
- \\
123.834 \\
108.345 \\
- \\
203.506 \\
158.609 \\
101.752 \\
128.326 \\
75.264 \\
537.450 \\
53.750 \\
462.522\end{array}$ & $\begin{array}{r}38 \\
51 \\
41 \\
53 \\
43 \\
46 \\
- \\
52 \\
39 \\
31 \\
- \\
34 \\
35 \\
- \\
21 \\
27 \\
37 \\
33 \\
44 \\
3 \\
49 \\
7\end{array}$ & $\begin{array}{r}3.057 .894 \\
93.516 \\
50.022 \\
112.871 \\
- \\
94.568 \\
78.743 \\
- \\
31.517 \\
154.288 \\
214.210 \\
- \\
125.565 \\
95.589 \\
45.372 \\
171.558 \\
204.274 \\
138.821 \\
186.758 \\
76.071 \\
658.659 \\
62.425 \\
462.977\end{array}$ & $\begin{array}{r}42 \\
52 \\
37 \\
- \\
41 \\
43 \\
- \\
55 \\
28 \\
20 \\
- \\
36 \\
40 \\
54 \\
26 \\
22 \\
34 \\
23 \\
44 \\
3 \\
49 \\
5\end{array}$ & $\begin{array}{r}7.712 .160 \\
103.172 \\
93.096 \\
450.760 \\
- \\
123.397 \\
211.958 \\
53.121 \\
92.763 \\
336.506 \\
382.673 \\
96.167 \\
503.276 \\
228.098 \\
89.091 \\
284.861 \\
631.892 \\
300.050 \\
403.284 \\
100.797 \\
2.262 .375 \\
115.327 \\
849.496\end{array}$ & $\begin{array}{r}50 \\
53 \\
19 \\
- \\
48 \\
40 \\
58 \\
54 \\
29 \\
21 \\
52 \\
15 \\
38 \\
56 \\
33 \\
10 \\
32 \\
20 \\
51 \\
2 \\
49 \\
7\end{array}$ \\
\hline
\end{tabular}

en 1785, Menorca en 1795 y Solsona en 1593; Ceuta pasa a Castilla en 1668, después de la secesión de Portugal; Santander se crea en 1754, Tudela en 1783 y Valladolid en 1595. 


\begin{tabular}{|c|c|c|c|c|c|c|}
\hline Corona de Castilla: & 10.737 .006 & & 10.737 .229 & & 20.324 .214 & \\
\hline - Almería & 63.696 & 48 & 60.179 & 50 & 202.708 & 41 \\
\hline - Astorga & 146.664 & 29 & 107.646 & 38 & 243.489 & 36 \\
\hline - Ávila & 191.628 & 22 & 147.302 & 31 & 228.446 & 37 \\
\hline - Badajoz & 190.440 & 23 & 151.233 & 30 & 267.593 & 35 \\
\hline - Burgos & 407.350 & 11 & 357.172 & 14 & 477.990 & 16 \\
\hline - Cádiz & 139.978 & 30 & 153.832 & 29 & 315.591 & 30 \\
\hline - Calahorra & 166.713 & 26 & 218.783 & 22 & 362.928 & 24 \\
\hline - Canarias & 149.625 & 28 & 251.826 & 17 & 461.497 & 17 \\
\hline - Cartagena & 189.313 & 24 & 264.385 & 15 & 572.717 & 14 \\
\hline - Ceuta & - & - & 52.236 & 51 & 90.000 & 55 \\
\hline - Ciudad Rodrigo & 107.408 & 36 & 64.768 & 47 & 83.757 & 57 \\
\hline - Córdoba & 474.907 & 5 & 404.384 & 8 & 716.420 & 9 \\
\hline - Coria & 238.834 & 18 & 241.309 & 18 & 361.373 & 25 \\
\hline - Cuenca & 464.045 & 6 & 395.378 & 11 & 580.974 & 13 \\
\hline - Granada & 273.356 & 16 & 373.007 & 12 & 849.603 & 6 \\
\hline - Guadix & 72.071 & 45 & 67.147 & 46 & 161.591 & 45 \\
\hline - Jaén & 297.773 & 14 & 364.011 & 13 & 603.944 & 12 \\
\hline - León & 185.195 & 25 & 143.046 & 33 & 224.610 & 39 \\
\hline - Lugo & 80.702 & 42 & 70.448 & 45 & 178.250 & 43 \\
\hline - Málaga & 311.255 & 13 & 445.564 & 6 & 935.759 & 5 \\
\hline - Mondoñedo & 47.667 & 50 & 49.123 & 53 & 156.709 & 46 \\
\hline - Orense & 84.334 & 40 & 63.637 & 48 & 191.207 & 42 \\
\hline - Osma & 235.843 & 19 & 211.793 & 21 & 353.224 & 28 \\
\hline - Oviedo & 134.959 & 32 & 184.049 & 25 & 353.787 & 27 \\
\hline - Palencia & 319.410 & 12 & 161.243 & 27 & 308.549 & 31 \\
\hline - Pamplona & 407.450 & 10 & 376.137 & 7 & 451.728 & 18 \\
\hline - Plasencia & 423.821 & 9 & 399.188 & 10 & 604.465 & 11 \\
\hline - Salamanca & 274.213 & 15 & 186.379 & 24 & 382.151 & 22 \\
\hline - Santander & - & - & - & - & 137.041 & 47 \\
\hline - Santiago & 520.631 & 4 & 573.431 & 4 & 1.453 .366 & 4 \\
\hline - Segovia & 263.652 & 17 & 263.923 & 16 & 368.393 & 23 \\
\hline - Sevilla & 853.284 & 2 & 930.566 & 2 & 1.690 .907 & 3 \\
\hline - Sigüenza & 440.028 & 8 & 402.405 & 9 & 767.740 & 8 \\
\hline - Toledo & 2.288 .114 & 1 & 2.220 .815 & 1 & 4.345 .944 & 1 \\
\hline - Tudela & - & - & - & - & 42.298 & 59 \\
\hline - Tuy & 69.654 & 47 & 101.763 & 39 & 177.491 & 44 \\
\hline - Valladolid & - & - & 132.652 & 35 & 268.887 & 34 \\
\hline - Zamora & 222.983 & 20 & 146.468 & 32 & 360.087 & 26 \\
\hline España & 13.361 .705 & & 13.795 .123 & & 28.036 .374 & \\
\hline
\end{tabular}

\section{LAS PENSIONES SOBRE LAS RENTAS}

La Curia romana admitía que el monarca español, al hacer la presentación de cada nuevo obispo que iba a cubrir una sede vacante, pudiera reservarse hasta la tercera parte de la renta líquida. En teoría esa porción era asignada por Roma a los cardenales que tenían escasas rentas y, en segundo lugar, a los sujetos que el monarca quería 
agraciar. En la práctica, sin embargo, era el rey quien designaba a las personas que deseaba beneficiar con esta gratificación y el papa se limitaba a extender la bula con la autorización canónica para el disfrute de la pensión ${ }^{36}$.

La Secretaría del Real Patronato era quien marcaba las reglas sobre las pensiones, tanto en su imposición como en su distribución. Cuando moría o renunciaba un obispo a la sede, la Secretaría pedía a la Iglesia, sede vacante, relación de los valores de la mitra en el último quinquenio, liquidándose según ellos el importe medio anual. De esta cantidad o renta bruta se descontaban las cargas y gastos fijos anteriormente descritos y se deducía la tercera o cuarta parte, que era la cantidad que el rey acostumbraba reservar al hacer la presentación del nuevo obispo a Roma ${ }^{37}$.

Estas pensiones se cargaban al mismo tiempo de hacer la presentación de cada nuevo obispo a Roma. El obispo electo, al aceptar el obispado debía prestar también su consentimiento a las pensiones cargadas sobre él y comprometerse a pagar su importe a los pensionistas desde el día en que el papa le pasase la gracia del obispado. En consecuencia, a la vista del despacho de presentación real y del consentimiento de las pensiones por el electo, la Curia romana expedía las bulas de nombramiento, indicando el importe de las pensiones que se habían impuesto a favor de las personas que el monarca nombrase con estas o similares palabras: «Proveemos la expresada Iglesia de Burgos en ti Ramón José de Arce (1797), sobre cuya mesa episcopal y sus frutos, rentas y productos hemos concedido el día de hoy que se reserve una o más pensiones anuales, hasta la cantidad de 5.727 ducados de oro de cámara y 9 julios de moneda romana, para las personas que en cualquier tiempo se nombrasen por Nos o por el Pontífice romano que en adelante fuera, y que sean del agrado y aceptación del mencionado rey Carlos» ${ }^{38}$.

Aunque la Curia romana autorizaba que las pensiones cargadas importasen hasta la tercera parte de la renta líquida, sin que ésta fuera rebasada, no siempre se imponía a razón de la tercera parte. El año 1611 el monarca ordenó que «de aquí en adelante no se señale en ningún obispado de su real presentación más cantidad de pensión que hasta la cuarta parte de los frutos» ${ }^{39} \mathrm{y}$, en líneas generales, así se practicó hasta los últimos años del siglo, en que se impuso la tercera parte a los obispados ricos y medianos. Las reales órdenes de 16 de noviembre de 1712 y 31 de marzo de 1713 disponen que los

36. Muchas de estas bulas se encuentran en AHN, Consejos, legs. 16980, 16983, 16987, 17001, 17017, $17025,17031,17039,17046,17062,17066$, etc.

37. Sobre las pensiones ver los trabajos de Cloulas, I.: «La Monarquie Catholique et les revénus episcopaux: Les pensions sur les Mitres de Castille pendant le régne de Philippe II», Mélanges de la Casa de Velázquez, 4 (1968), pp. 107-142; FernáNDEZ, L.: «Pensiones a favor de eclesiásticos extranjeros cargadas sobre las diócesis de la Corona de Castilla», Hispania, 34 (1974), pp. 507-577; y las páginas que dedica al tema Hermann, Ch.: L'Eglise d'Espagna sous le patronage royal (1476-1834), Madrid, Casa Velázquez, 1988, pp. 165-180.

38. AHN, Consejos, leg. 16987.

39. Ibíd., leg. 19412. Real orden de 15 de octubre de 1611 sobre la forma de distribuir las pensiones de los obispos, firmada por el duque de Lerma. 
obispos electos presten su consentimiento a la tercera parte de la renta líquida para salvaguardar la regalía del monarca, aunque sólo se imponga a razón de la cuarta parte ${ }^{40}$.

Este era el marco legal, pero ¿cuál es la realidad? Hasta finales del seiscientos la praxis más normal es que sólo se imponga la tercera parte a los ricos, la cuarta a los medianos y a los pobres nada. En el setecientos se impone la tercera parte también a los medianos y desde finales del siglo la carga de la tercera parte se hace general a la mayoría de los obispos por la fuerte subida que experimentan las rentas. Este esquema, válido a nivel general, requiere algunas matizaciones A los obispados aragoneses de Albarracín, Tarazona, Teruel y Zaragoza se suele imponer a razón de la tercera parte de la renta líquida, a Huesca la cuarta parte, a Barbastro una cantidad fija de unos seis mil reales hasta 1750, en que se comenzó a imponer la cuarta parte, y Jaca estuvo exenta de pensión por la cortedad de sus rentas hasta 1785, en que se le agregó el partido de la Valdonsella, que antes pertenecía a Pamplona ${ }^{41}$, y se le carga la tercera parte. A los catalanes de Barcelona, Gerona, Lérida, Tarragona y Tortosa no se acostumbra a cargar más que una cantidad próxima a la cuarta parte hasta finales del siglo XVII, «por alivio de los prelados y en atención a los gastos que se ofrecen en bulas y de percibir los frutos», pero luego se impuso a razón de la tercera parte. Sobre Solsona, Urgel y Vic se solía imponer una pequeña cantidad fija hasta la segunda mitad del siglo XVIII, en que se comenzó a cargar hasta la tercera parte. Al obispo de Mallorca se le grava con la tercera parte desde finales del seiscientos, pero los de Ibiza y Menorca están exentos de pensión. A los obispados valencianos se les impone a razón de la tercera parte, pero al de Segorbe, «por su corto valor y la mucha pobreza de sus pueblos», sólo se impuso la cuarta parte en la primera mitad del setecientos, y en la provisión de 1707 únicamente se cargaron los 5.250 reales de las pensiones existentes (el 6,5\% de la renta líquida), «en atención al atraso y quiebras que padeció este obispado en sus rentas con las inquietudes de Valencia» ${ }^{42}$.

En los obispados castellanos también existían diferencias. A los andaluces de Córdoba, Granada, Jaén, Málaga y Sevilla se impone la tercera parte. A Cádiz se acostumbra a cargar la cuarta parte hasta 1801, «sin duda por lo corto que fue su valor en tiempos pasados», pero a partir de aquí se impone la tercera. Las rentas episcopales de Almería estuvieron exentas de pensión por su escaso valor hasta 1798, en que se gravan con 36.000 reales a favor de la casa de niños expósitos de Santander. Al obispo de Guadix tampoco se impuso pensión «por la cortedad de sus rentas y pobreza de aquel país» hasta 1804, en que se le grava con trescientas fanegas de pan, mitad trigo y cebada, y seis mil reales a favor de la Casa de misericordia de Guadix, a la que se sumó en 1824 otra pensión de 4.400 reales para Toribio de Ugarte, «en compensación de los méritos y padecimientos de su difunto padre, ministro que fue del Consejo de

\footnotetext{
40. Ibíd., leg. 16978. Cámara a Felipe V. Madrid 27 enero 1723.

41. GoÑ Gaztambide, J.: Historia de los obispos de Pamplona, VIII. Siglo XVIII, Pamplona 1989, pp. 205225 y $235-242$.

42. AHN, Consejos, leg. 19361.
} 
Guerra ${ }^{43}$. Ceuta estaba exenta de pensión. Al obispado de Canarias se imponía a razón de la cuarta parte «por ser de los medianos de renta y en atención a la pobreza de las islas»».

A los ricos obispados de Castilla la Nueva (Cuenca, Sigüenza y Toledo) se carga la tercera parte, pero ante la dificultad de liquidar el valor de la mesa arzobispal de Toledo, se acostumbraba que el electo consintiera setenta mil ducados de pensión, aunque cuando se lograba averiguar su importe sólo se cargaba la tercera parte, como sucede en 1720 cuando se nombró a Diego de Astorga que, «a pesar de haber consentido los setenta mil ducados, habiéndose logrado liquidar el valor fijo, que importaba 163.932 ducados de vellón, en los que sólo cabían 54.644 ducados por la tercera parte, el monarca resolvió que no se le impusiera más pensión que la tercera parte» ${ }^{44}$.

A los de Castilla la Vieja y León, considerados medianos, se solía imponer a razón de la cuarta parte en el seiscientos, pero desde principios del setecientos se carga la tercera parte a los de Burgos, Calahorra, Salamanca y Segovia; práctica que se hizo extensiva a los demás en la segunda mitad del siglo, a excepción de Ciudad Rodrigo que, por su corta renta, se respetó la costumbre de imponerle sólo unos seis mil reales.

Sobre los obispados extremeños se acostumbra a cargar a razón de la tercera parte al rico de Plasencia y de la cuarta a los medianos de Badajoz y Coria, aunque al último se impuso la tercera parte a partir de 1713. Al de Badajoz, que se acostumbraba a cargar la cuarta parte, desde 1640 hasta 1673 sólo se imponen cuarenta mil reales, «en atención a estar este obispado en la frontera de Portugal, a la autoridad de aquella iglesia y a ser plaza de armas, donde hay soldados que socorrer». En 1706 y 1708 no se carga ninguna pensión por los efectos de la guerra, pero en 1715 se volvió a cargar la cuarta parte y a partir de 1797 la tercera ${ }^{45}$.

En Galicia sólo se impone la tercera parte al arzobispo de Santiago de Compostela. El obispado de Lugo, «por su corto valor, pobreza del país y la obligación de proveer de todo lo necesario a algunas iglesias del obispado», estuvo exento de pensión hasta 1814, en que se imponen 25.860 reales (10,9\% de la renta líquida) a favor de la universidad de Valladolid y dos clérigos ${ }^{46}$. Las rentas del obispo de Tuy sólo se gravan de forma ocasional hasta mediados del setecientos, pero a partir de 1751 se impone a razón de la cuarta parte ${ }^{47}$. Los obispos de Modoñedo y Orense estaban exentos por la cortedad de sus rentas y pobreza del obispado, aunque debían prestar su consentimiento a la tercera parte para preservar la regalía del monarca ${ }^{48}$.

43. Ibíd., leg. 17012. La exención de pensiones se rompe en 1701 y 1750 , en que sus prelados renuncian a la mitra y se impone una pensión de 22.000 y 9.857 reales para la congrua sustentación de los obispos dimisionarios.

44. Ibíd., leg. 17057: Informe de la Cámara. Madrid 9 marzo 1734.

45. Ibíd., leg. 16984.

46. Ibíd., leg. 17018.

47. Ibíd., leg. 17060. De 1654 a 1668 se dieron 5.500 reales de pensión al cardenal Ciro, y de 1720 a 1722 otra de 22.000 para el obispo dimisionario.

48. Ibíd., leg. 17023. 
Por último, al obispo de Cartagena se le carga a razón de la cuarta parte hasta finales del seiscientos, pero en 1695, «al haber tantos a quienes atender y socorrer por este medio», se imponen al electo pensiones por valor de casi el treinta por ciento de la renta líquida y a sus sucesores a razón de la tercera parte. Algo similar sucede al de Pamplona, que en el seiscientos se le grava con la cuarta parte, pero desde 1711 se hace en función de la tercera. De nada sirvió que el prelado representase al monarca en 1716 que, «al ser este obispado uno de los medianos en renta siempre se le había cargado la pensión por la cuarta parte», pues se impuso la tercera y así continuó en adelante ${ }^{49}$.

El análisis de los datos que aportan las relaciones de valores enviadas a la Secretaría del Real Patronato y los que aparecen en las actas consistoriales permite conocer el importe de las pensiones impuestas a los obispos y su evolución a lo largo de casi tres siglos; y de forma aproximada se puede afirmar que su cuantía sube considerablemente a lo largo del periodo en términos absolutos y relativos, de tal manera que los 2.727.167 reales de 1566-1599 se multiplican casi por tres en 1750-1834, y su porcentaje dentro de la renta líquida pasa del 20,4 al 28,3 por 100, según se especifica a continuación:

Cuadro 4. Importe de las pensiones

(Media anual en reales de vellón)

\begin{tabular}{|c|c|c|c|c|c|c|}
\hline \multirow{2}{*}{ Periodo } & \multicolumn{2}{|c|}{$\begin{array}{c}\text { Corona de Aragón } \\
\text { Reales \% }\end{array}$} & \multicolumn{2}{c|}{$\begin{array}{c}\text { Corona de Castilla } \\
\text { Reales \% }\end{array}$} & \multicolumn{2}{c|}{$\begin{array}{c}\text { España } \\
\text { Reales \% }\end{array}$} \\
\hline $1566-1599$ & 596.456 & 22,7 & 2.130 .711 & 19,8 & 2.727 .167 & 20,4 \\
\hline $1600-1749$ & 788.077 & 25,8 & 3.009 .945 & 28,0 & 3.798 .022 & 27,5 \\
\hline $1750-1834$ & 2.313 .592 & 30,0 & 5.625 .494 & 27,7 & 7.939 .086 & 28,3 \\
\hline
\end{tabular}

Aunque teóricamente las pensiones impuestas no podían sobrepasar la tercera parte de la renta líquida, en algunos casos concretos los prelados se ven precisados a consentir un porcentaje mayor. En los siglos XVII y XVIII esta violación de la normativa legal es algo excepcional y la mayoría de los prelados lo aceptan sin ninguna réplica, otros protestan y alguno rechaza el obispado o amenaza con dimitir por esta causa. La protesta se dirige a la Curia romana o a la Cámara de Castilla. En el primer caso se limitan a quejarse de que las pensiones existentes exceden a la tercera parte, como hace Baltasar Cernuda, electo de Plasencia en 1712, afirmando que el exceso es de 13.200 reales por la calamidad de los tiempos y el corto valor que han tenido los frutos del obispado en el último quinquenio ${ }^{50}$. En el segundo caso se encuentra Antonio Palafox, electo de Cuenca en 1801, que dice a la Cámara que los 165.111 reales de pensiones impuestas exceden a la tercera parte y pide que se haga una nueva valoración de las rentas de acuerdo con los tres quinquenios anteriores, pues los valores de 1794-

49. Ibíd., leg. 17032.

50. Ibíd., leg. 17953. 
1798 no podían servir de regla por el excesivo precio que habían tenido los granos. La Cámara aceptó la petición y mandó hacer una valoración de las rentas durante los últimos veinte años (1779-1798) y los resultados perjudicaron todavía más al prelado, pues la tercera parte resultante se elevaba a 252.406 reales $^{51}$.

No faltan algunos electos que rechazan el obispado por no prestar su consentimiento al exceso de pensiones. El franciscano José García, presentado al obispado de Málaga en 1724, lo rechaza por no aceptar los 323.851 reales de pensiones impuestas (135.619 que ya existían y 188.232 concedidos al cardenal Alberoni por su renuncia), que suponían el 64 por 100 de la renta líquida. El electo escribió a la Cámara para justificar su conducta, afirmando que con estas pensiones era imposible mantenerse con dignidad, según los informes que había recibido de los gastos del obispado, y solicita su rebaja o, en caso contrario, que se nombre un administrador que se haga cargo de cobrar las rentas episcopales, pagar los salarios de los ministros y familiares del obispo, dar la limosna acostumbrada y pagar las pensiones, quedando él desembarazado de estos cuidados materiales para poder cumplir mejor con las obligaciones espirituales, sirviendo el ministerio episcopal sin ser gravoso a la diócesis, «morando en el convento de mi religión y por cuenta de la providencia divina, como hijo de san Francisco» ${ }^{52}$. La Cámara no aceptó las condiciones y nombró a Diego de Toro, que consintió las pensiones impuestas, aunque excedían a la tercera parte en más de 88.000 reales. Unos años antes, el arzobispo de Santiago, Antonio Monroy, amenazó con dimitir si no le rebajaban las pensiones impuestas, afirmando que cuando se le dio el obispado en 1685 valía 462.000 reales, pero los miembros de la Cámara, al ver que no cabían en la tercera parte las pensiones que pretendían imponer, fabricaron otra valoración que elevaba la renta a 550.000 reales. La Cámara, molesta por la acusación, replicó que había utilizado el valor del quinquenio 1675-1679, en que las rentas importaron 544.434 reales, porque no había recibido otra valoración posterior ${ }^{53}$.

Esta violación de la normativa legal deja de ser algo excepcional y se convierte en normal en las primeras décadas del siglo XIX, de tal manera que las pensiones superan en la mayor parte de los casos la tercera parte y en algunos la mitad de la renta líquida. La explicación de esta situación, que violaba la normativa de la Curia romana, hay que buscarla en los elevados ingresos que las mesas episcopales obtienen en los últimos años del siglo XVIII y primeros del XIX, lo que motivó que la tercera parte correspondiente a las pensiones fuera también muy alta. Además, como en estos años la Secretaría del Real Patronato tendió a imponer pensiones con carácter de perpetuidad a favor de instituciones de distinto tipo, el importe de las pensiones vivas se mantuvo prácticamente estabilizado durante todo el periodo, mientras que la renta líquida de los obispos descendió bruscamente, lo que determinó que la tercera parte inicial se trasformase años después en el cuarenta o cincuenta por ciento. Ante esta situación,

51. Ibíd., leg. 17007. Informe de la Cámara. Aranjuez 8 marzo 1801.

52. Ibíd., leg. 17019.

53. Ibíd., leg. 15283. 
los obispos hicieron repetidas instancias a la Cámara para que los dispensase de pagar el importe que excedía de la tercera parte, y en cierta medida lo consiguieron con la circular de 13 de julio de 1727, que dispuso que las pensiones que superasen la tercera parte «se rebajen a prorrata entre los pensionistas», aunque la resolución del 1 de enero y 28 de diciembre de 1829 declaró que las pensiones perpetuas impuestas a favor de la Orden de Carlos III o aquellas destinadas al sostenimiento de establecimientos benéficos no estaban sujetas a rebaja.

La distribución de estas pensiones quedaba en manos del monarca que las repartía con carácter vitalicio a personas particulares del estamento eclesiástico y civil, o con carácter temporal o perpetuo a instituciones de distinto tipo (catedrales y colegiatas, hospitales, casas de niños expósitos, hospicios, seminarios, Orden de Carlos III, etc.). Hasta la segunda mitad del siglo XVIII predominan de forma abrumadora las primeras, pero luego se invierte la tendencia, de tal manera que el 30 por 100 que importan las pensiones que se conceden a instituciones en la primera mitad del XVIII, sube al 41 en la segunda mitad y al 53 en el primer tercio del XIX, porcentaje que en los obispados de la Corona de Aragón alcanza el 73 por $100^{54}$. Por tanto, las pensiones podían ser perpetuas, temporales y vitalicias. Las primeras suponían una enajenación a perpetuidad de una parte de la renta de los obispos y se concedían a comunidades eclesiásticas, iglesias del real patronato, hospitales y otras instituciones. Las segundas se daban a iglesias, comunidades o fundaciones para la restauración o conservación de sus edificios y ornato de sus sacristías por espacio de catorce años, pero de ordinario se concedían sucesivas prórrogas, con lo cual se convertían de hecho en perpetuas. Y las terceras se otorgaban de por vida a sujetos beneméritos.

El año 1744 el padre Fèvre, confesor de Felipe V, advierte al monarca del peligro que suponía para la regalía conceder pensiones perpetuas, cuyo importe «viene a ser como la cuarta parte de todas las pensiones concedidas en menos de treinta años; con que se evidencia que en menos de noventa años, sino se procura tener mayor cuidado y ponderación en semejantes concesiones, se hallarán asimismo apuradas las tres cuartas partes restantes». El problema se agravó por la facilidad con que se prorrogaban las temporales, pues con ello se impedía acudir con más pensiones vitalicias al remedio de tantas necesidades e instancias. Para evitar estos peligros el confesor propuso tres medidas: que no se concediesen pensiones perpetuas a favor de iglesias o comunidades, que no se prorrogasen las temporales con tanta facilidad y que se investigase en qué se había gastado el dinero cuando solicitaban la prórroga, «pues de ordinario, con la confianza de conseguir la prorrogación se gasta el dinero con menos economía». Respecto a las vitalicias indica que se evite utilizar la renta eclesiástica de las pensiones para usos profanos, y aconseja al rey que sólo se den a clérigos ordenados in $\operatorname{sacris}^{55}$.

Los beneficiarios de las pensiones son, por tanto, personas particulares e instituciones. A los primeros se les concede en concepto de merced real y como recompensa

54. Ibíd., leg. 19862.

55. AGS, Gracia y Justicia, leg. 291. 
por los servicios prestados a la Corona, lo que contribuyó a la formación de una especie de clientela en torno al real patronato; en cambio las segundas se conceden para financiar o potenciar la actividad cultual, asistencial, educativa y social, y la preponderancia que alcanzan desde mediados del setecientos responde a una política social de redistribución de las rentas.

Las personas que se benefician de las pensiones son clérigos españoles en su mayoría, pues la real orden del 15 de octubre de 1611 dispuso que estas pensiones se provean en clérigos, por lo menos de corona, que hayan sido útiles a la Iglesia, lo sean al presente o se espere que lo fueran. Y cuando estos requisitos concurran en ministros o criados del monarca o en sus hijos, «se tenga particular cuenta de ellos en la provisión de estas pensiones, y su cantidad se regule según la calidad, edad, necesidad y capacidad de cada uno, teniendo también en cuenta lo que toca a los ministros, a la dignidad y prerrogativa de los lugares en que sirvieron, y a los méritos y satisfacción con que lo hubieran hecho ${ }^{56}$. En 1715 Felipe V ordenó a la Cámara que no propusiese para pensiones a los que no tuviesen más de dieciocho años y clara inclinación al estado eclesiástico ${ }^{57}$, y en 1744 su confesor le aconsejó que para obviar los artificios de la codicia sólo se concediesen a ordenados in sacris, pues algunos individuos fingían vocación eclesiástica y con la excusa de necesitar ayuda para continuar los estudios pedían pensiones eclesiásticas y después las secularizaban con una bula pontificia, disfrutándola aunque se casasen, lo que era contrario a la finalidad que debían tener los bienes de la Iglesia ${ }^{58}$. Entre los beneficiarios se encuentran capellanes reales, confesores y predicadores de la familia real, prebendados de catedrales y colegiatas, caballeros de las órdenes militares, personal de la administración de la monarquía y familiares de cardenales, obispos y miembros de los consejos, y el importe de cada una de estas pensiones se sitúa entre mil y cinco mil reales. En un nivel más alto se hallan las que se conceden a oficiales de la Curia romana, inquisidores, obispos auxiliares y dimisionarios, miembros de los consejos y cardenales, etc.

En la segunda mitad del siglo XVI y primeros años del XVII son numerosas las que se otorgan a eclesiásticos extranjeros para pagar fidelidades y comprar voluntades. Sólo en el último tercio del XVI se imponen 1.583.021 reales de pensión sobre las mitras castellanas a favor de extranjeros, lo que supone el 74 por 100 de las que se cargan en estos años. En primer lugar, se agasaja a más de cincuenta cardenales de la Curia romana con pensiones por importe de 1.203.213 reales para afianzar el partido español en el Sacro Colegio. En segundo lugar, se conceden pensiones a treinta obispos italianos, flamencos, portugueses e ingleses por valor 223.960 reales para premiar servicios y comprar voluntades. En tercer lugar, se conceden 84.348 reales a treinta y cuatro clérigos alemanes, flamencos, franceses, italianos y portugueses que formaban parte de la capilla real o que convenía recompensar por sus servicios; y por último, se

56. AHN, Consejos, leg. 19412.

57. Novísima Recopilación, libro I, tít. 23, ley 8.

58. AGS, Gracia y Justicia, leg. 291. 
otorgan otros 71.500 reales a catorce seglares sirvientes de la capilla real o nepotes de cardenales de la Curia romana ${ }^{59}$.

A partir de 1630 las pensiones a favor de extranjeros descienden sensiblemente, aunque en mayor o menor cuantía siguieron estando presentes a lo largo del periodo. Ahora son los cardenales españoles pertenecientes a la familia real los que se benefician de las pensiones más altas: el cardenal Infante recibe 550.000 reales anuales de 1632 a 1641, Juan José de Austria 836.886 entre 1665 y 1679, y Luis de Borbón más de un millón de reales desde 1754, en que renuncia el cardenalato y los arzobispados de Sevilla y Toledo, hasta que muere en 1785. A gran distancia quedan los inquisidores generales, patriarcas de Indias, algunos príncipes y prelados italianos y alemanes, etc., que en la segunda mitad del setecientos apenas alcanzan los cien mil reales.

Las actividades institucionales que se benefician de pensiones son el culto, la asistencia social, la enseñanza y otras de carácter cívico. Las pensiones concedidas a catedrales, colegiatas, capillas reales, capillas de las embajadas de España ante las cortes no católicas, monasterios, conventos o parroquias, son las que tienen un origen más antiguo y en la primera mitad del setecientos absorben las dos terceras partes de las que se conceden a instituciones, bajando a la mitad a finales de la centuria y a poco más de un tercio en 1820 . No obstante su importe se duplica entre 1720 y 1820 , y pasa de novecientos mil a dos millones de reales. Las que se otorgan a hospitales, casas de niños expósitos, hospicios, casas de misericordia y montepíos, experimentan una subida espectacular en términos absolutos y relativos, pues en el periodo indicado suben de cuatrocientos mil a dos millones y medio de reales, y su porcentaje pasa del 22 al 40 por 100. Las universidades, seminarios, colegios y escuelas también son acreedoras de una partida cada vez mayor, pues los noventa mil reales de 1720 ascienden a ochocientos mil un siglo después, y su porcentaje sube del seis al quince por ciento. Por último, a partir de mediados del setecientos también se otorgan pensiones a la Orden de Carlos III, algunas sociedades económicas y otras instituciones de carácter cívico.

En muchas ocasiones los obispos eran remisos en el abono de las pensiones, y son frecuentes las quejas que los pensionistas elevan a la Cámara por el tardío y deficiente pago de las mismas, llegando en algunos casos a denunciar al prelado ante el tribunal de la Nunciatura, como sucedió a Baltasar de Mendoza, obispo de Segovia (16991727). Este prelado, al hacerse cargo de la mitra aceptó 79.365 reales de pensión, pero sus crecidas deudas le impidieron pagar a los pensionistas. En 1706 la Nunciatura convocó concurso de acreedores y embargó las rentas de la mitra para efectuar los pagos, pero los pensionistas, muchos de los cuales no habían cobrado nada desde 1699, tuvieron que hacer grandes rebajas y sólo recibieron 90.817 reales en vez de los 121.597 que les pertenecían ${ }^{60}$.

Ante las reiteradas quejas de los pensionistas por la resistencia de los prelados al abono puntual e integro de sus pensiones, la real cédula de 22 de agosto de 1716 tomó

59. AGS, Patronato Eclesiástico, legs. 135, 136 y 137.

60. ASV, Arch. Nunz. Madrid, vol. 68, ff. 201-203. 
algunas providencias para poner remedio a las extorsiones que continuamente padecían, porque los obispos pagaban las pensiones con un año de retraso y descontaban la tercera o cuarta parte de su importe ${ }^{61}$. Pero poco se consiguió, las quejas continuaron repitiéndose y el rey se decidió a intervenir en 1746 con un decreto sobre la forma que debían guardar los prelados en el pago de las pensiones para evitar los perjuicios que recibían las instituciones y los particulares en la percepción de la cantidad que cada uno tenía concedida, «por las bajas que los prelados hacen con el pretexto de subsidio y excusado, gastos de administración, recolección de frutos, reducción de ellos a dinero y cobranza de las rentas de la mitra». En consecuencia, para corregir este inveterado abuso, ordenó a los prelados «que se pague a los pensionistas el importe íntegro, en dinero efectivo y en la capital del obispado, sin más demora que dieciocho meses para la primera paga y seis más para cada una de las siguientes, y sin otra baja que la que por razón de subsidio y excusado corresponda a la cantidad de pensión asignada a cada uno» ${ }^{62}$.

En los años sucesivos, a pesar del real decreto y de los apremios de la Cámara, la prontitud y exactitud en su paga dependió en buena medida de la fluctuación de los ingresos de la mitra; por ello, cuando a principios del siglo XIX comenzaron a descender sus rentas y la crisis de subsistencia hizo acto de presencia, los prelados se mostraron remisos en su abono con el pretexto de tener que ayudar a los diocesanos más necesitados. Y además, elevaron instancias a la Cámara para que los dispensase de pagar el importe que superase la tercera parte, que en cierto modo consiguieron con la circular de 13 de julio de 1827, como antes se indicó.

\section{LA RENTA DISPONIBLE POS LOS OBISPOS Y SU INVERSIÓN}

Si del importe de la renta líquida se descuentan las pensiones, se obtiene la renta disponible que quedaba a los obispos. Los datos del cuadro quinto muestran que su comportamiento es similar al que se registra en la renta líquida, aunque la caída del siglo XVII es mayor, sobre todo en Castilla, y la recuperación del XVIII más lenta y menos elevada por la fuerte subida que experimentan las pensiones.

Cuadro 5. Importe de la renta disponible

(Media anual en reales de vellón)

\begin{tabular}{|c|c|r|r|r|r|r|}
\hline Periodo & \multicolumn{2}{|c|}{$\begin{array}{c}\text { Corona de Aragón } \\
\text { Reales Índice }\end{array}$} & \multicolumn{2}{|c|}{$\begin{array}{c}\text { Corona de Castilla } \\
\text { Reales Índice }\end{array}$} & \multicolumn{2}{|c|}{$\begin{array}{c}\text { España } \\
\text { Reales Índice }\end{array}$} \\
\hline $1566-1599$ & 2.028 .243 & 100,0 & 8.606 .295 & 100,0 & 10.634 .538 & 100,0 \\
\hline $1600-1749$ & 2.269 .817 & 111,9 & 7.727 .284 & 89,8 & 9.997 .101 & 94,0 \\
\hline $1750-1834$ & 5.398 .568 & 266,2 & 14.698 .720 & 170,8 & 20.097 .288 & 189,0 \\
\hline
\end{tabular}

61. AHN, Consejos, leg. 19003.

62. ASV, Arch, Nunz. Madrid, vol. 97, f. 359. 
La distribución de esta renta entre los obispos es muy desigual y en líneas generales es similar a la que se indicó al hablar de la renta líquida. Por esta razón su cuantía, más que suficiente para los prelados que ocupan sedes ricas o medianas, en ocasiones resulta insuficiente para sufragar las necesidades de los prelados de algunas sedes modestas. En 1687 el obispo de Almería se encuentra falto de medios para sustentar su casa y pide ayuda al rey, como patrono que era del obispado,

«pues es tanta la necesidad que no tiene en el día de hoy para sustentarse, y en cuatro años que ha que fue servido honrarme con este obispado no he podido conseguir un coche de dos mulas para ir a la iglesia, y esto a vista de tanta nación extranjera que acude a este puerto, a quien no ha de dejar de ser un gran reparo y nota el que en los dominios de su majestad se halle un obispo con tanta estrechez $\rangle^{63}$.

Algo similar ocurre al de Ceuta, pues con sus cortos medios no podía atender los gastos indispensables de casa, el socorro de los pobres que pedían pan y el pago a los acreedores que le prestaron dinero para su consagración ${ }^{64}$. El obispo electo de Gerona, José Taberner, al aceptar el nombramiento, pide a la Cámara el 21 de febrero de 1720 que no le cargue nuevas pensiones, porque después de pagar las existentes, apenas le quedaba suficiente para el decente sustento de su familia y socorrer a los pobres ${ }^{65}$.

El excedente que cada año quedaba a los prelados lo empleaban en pagar los salarios de los oficiales y dependientes de la administración diocesana, del gobierno y funcionamiento de su casa, alimentación y vestuario, limosnas que hacían y otros conceptos varios. Los obispos para llevar a cabo su ministerio pastoral y de gobierno se auxilian de unos colabores a los que abonan un determinado salario. Su número, si exceptuamos los ricos y extensos obispados de Toledo, Sevilla o Valencia, se reduce por lo general al provisor y vicario general, secretario de cámara, fiscal, procurador, visitador y algún otro oficial. El importe del salario que reciben es muy similar y permanece estabilizado hasta la segunda mitad del setecientos en torno a los doce mil reales, luego experimenta una importante subida y se duplica a principios del ochocientos. En Sevilla los oficiales y dependientes de la administración diocesana en el último tercio del setecientos son 24 y su salario importa 80.000 reales; en Toledo son 29 y, con la inclusión del salario que se daba al obispo auxiliar, supera los 150.000 reales en la misma época ${ }^{66}$.

El gobierno y cuidado de la casa episcopal estaba a cargo del mayordomo, que lleva cuenta de los gastos, cuida del vestuario y de los servidores y criados, provee lo necesario para la alimentación y buena marcha de la casa, y hace las reparaciones que era menester en los palacios y casas de la dignidad. Andrés Passano, al hablar de Moscoso Sandoval, arzobispo de Toledo (1646-1665), dice que el perfecto gobierno de

63. AHN, Consejos, leg. 16978. Obispo de Almería a Carlos II. Almería 15 febrero 1687.

64. Ibíd., leg. 17013. Obispo de Ceuta a Fernando VII. Ceuta 24 noviembre 1827.

65. Ibíd., leg. 19573.

66. Barrio Gozalo, M.: «Perfil socio-económico de una elite de poder, V. Los obispos de Andalucía (16601840)», Antholica Annua, 34 (1987), p. 289. 
la casa debía apoyarse en el mayordomo, camarero, caballerizo y maestro de pajes, sin que ninguno se entremeta en la labor de los otros ${ }^{67}$.

El número de criados y dependientes varía según el estilo de vida de cada obispo, aunque siempre es elevado. En los obispados de tipo medio se sitúa en torno a 25, y entre ellos se encuentran capellanes, cocineros y reposteros, cocheros, criados, médico, pajes y portero, y el salario que reciben suma unos treinta mil reales. En Sevilla el número es mayor y los gastos también. El cardenal Solís (1755-1775), que llevaba un elevado tren de vida, estaba rodeado de una corte de 75 empleados y dependientes, a los que abonaba 176.020 reales en concepto de salario, que durante el pontificado de Marcos de Llanes (1783-1795) bajaron a 149.485. En Toledo el número también era elevado y durante el pontificado del cardenal Lorenzana (1772-1800) los salarios del personal de servicio de la casa de Madrid importan sesenta mil reales, y más de cien mil los del palacio de Toledo.

A estos gastos hay que sumar el capítulo de la alimentación y vestuario, los reparos habituales en las casas episcopales, alquiler de ella cuando no la tenían y los gastos extraordinarios. A mediados del siglo XVIII el obispo de Segovia se conforma con 36.073 reales para alimentación ${ }^{68}$; el de Orense requiere 64.000 para el gasto diario de su manutención y familia, «con inclusión del extraordinario de las funciones pontificales $\rangle^{69}$, y el de Málaga calcula en 132.000 los gastos precisos para mantenerse con su familia, con la dignidad y decencia que lo habían hecho los prelados moderados,

«porque además de ser la ciudad de Málaga una de las primeras de Andalucía, se añade el ser puerto de mar, en que están de asiento los cónsules de todas las naciones y concurren muchas veces los generales de las armadas, a quienes han cortejado, regalado y convidado siempre los obispos de Málaga, librando a la ciudad su obligación en ellos» ${ }^{70}$.

El arzobispo de Sevilla Marcos de Llanes precisa casi doscientos mil, mientras que al Toledo le basta con 127.288 en 1796, aunque cinco años después el cardenal Borbón necesita 246.792 para este menester.

Las limosnas que repartían diariamente a los pobres y necesitados a la puerta del palacio absorbían cada año una parte importante de las rentas, pues los pobres eran los principales acreedores de los bines eclesiásticos. Como dice el obispo de Astorga en 1660, «si no socorro a los muchos pobres que hay en la ciudad y en todo el obispado perecen de hambre, porque esta tierra es pobrísima y más lo está ahora que nunca con la infinidad de tributos que sobre si tiene, y con los años malos y estériles a todos los

67. Passano de Haro, P.: Exemplar eterno de prelados impresos en el corazón y ejecutado en la vida y acciones del Emmo. Sr. don Baltasar de Moscoso Sandoval, Toledo, Francisco Calvo, 1670, p. 119.

68. Archivo Diocesano de Segovia, Est. 2, leg. 16.

69. AHN, Consejos, leg. 17023.

70. Ibíd., leg. 17019. Esta cantidad está muy próxima a los 121.000 reales que en 1687 juzga necesarios el tesorero del obispo para «el sustento de la casa y familia del obispo», a los que había que añadir mil fanegas de trigo para gasto de casa del obispo y seiscientas de cebada para gasto de las mulas. Cf. ASV, Arch. Nunz. Madrid, vol. 14, f. 904r. 
tiene acabados y consumidos» ${ }^{71}$. Algo parecido afirma el de Gerona en 1720, al indicar que regularmente van a la puerta de palacio de mil a mil quinientos pobres, «a los cuales sin un notable escándalo y faltar a la obligación de un prelado no puede ni debe dejar de dar limosna» ${ }^{72}$. A estas limosnas ordinarias hay que sumar las que de forma privada entregan a pobres vergonzantes y necesitados, así como los desembolsos que realizan en la fundación, ampliación o consolidación de diferentes obras de carácter asistencial, cultural o religioso, como casas de mujeres recogidas o de misericordia, escuelas o iglesias.

Por último, no se deben olvidar los muchos gastos que tenían que hacer para pagar las bulas, la mesada eclesiástica y los gastos que originaba la consagración, el viaje a su iglesia, amueblar la casa episcopal y la toma de posesión. Es decir, una vez que el electo recibía el nombramiento tenía que comenzar a buscar dinero para comprar los hábitos e insignias episcopales (báculo, mitra, anillo, vestidos de viaje y de ceremonia), vajilla de plata y ropas para casa, carrozas, caballos, contratar servidores, etc., y realizar el viaje a la diócesis, que en el caso de Canarias, además de caro y difícultoso, constituía una auténtica aventura. Joaquín Herrera, preconizado obispo de Canarias en 1779, se gastó en pagar los derechos de nombramiento, consagración, pontificales, viaje, comprar algunos géneros para vestir y adornar la casa algo más de 225.000 reales, casi la renta de un año ${ }^{73}$. En 1677 Alfonso de los Ríos gastó en el traslado de Ciudad Rodrigo a Granada algo más de 140.000 reales, en concepto de viaje, posadas, compra de carrozas y mulas, alhajas y mobiliario para la nueva casa ${ }^{74}$.

En fin, si a los conceptos indicados se suman las ayudas que prestaban a diferentes párrocos para su congrua sustentación, las aportaciones para reparación iglesias y las limosnas que hacían a los campesinos para que en los años de malas cosechas pudieran sembrar, veríamos que en muchas ocasiones los gastos igualaban a los ingresos, al menos en las mitras menos ricas. Incluso los titulares de Toledo, Sevilla, Córdoba, Cuenca, Granada, Jaén, Málaga, Plasencia o Sigüenza se quejan en las épocas de crisis de su incapacidad para hacer frente a las cargas que pesaban sobre sus rentas y esto, según dice el arzobispo de Toledo a principios del siglo XIX, «sin haber depositado jamás los rendimientos de la mitra en arcas para conservarlos al año siguiente, sino que se han depositado, según los preceptos del Evangelio, en donde ni el moho ni la polilla los carcome y consume» ${ }^{75}$. Idénticos lamentos escuchamos a los demás prelados, sobre todo en los momentos críticos de la segunda mitad del siglo XVII, cuando en 1680 se

71. AHN, Consejos, leg. 16979. Obispo de Astorga a Cámara. Astorga 11 febrero 1660.

72. Ibíd., leg. 19573.

73. Archivo Histórico Diocesano de Canarias, 16, 5/2. Libro de gastos del palacio del Ilmo. Sr. Herrera. Año 1778.

74. Biblioteca Universitaria de Granada, B-37-17-2.

75. Archivo Diocesano de Toledo, Borbón, leg. 64. 
les quiso imponer una décima a favor del emperador ${ }^{76}$, y más aún en los años 18201834 por el exceso de las pensiones y el descenso de las rentas episcopales.

Para concluir diré que, de acuerdo con el axioma de que cuanto sobrase al obispo de su decente sustentación y del cumplimiento de su ministerio pertenecía a los pobres por derecho propio ${ }^{77}$, la mayor parte de los prelados que rigen las sedes españolas en la época moderna invierten buena parte de sus excedentes en el desarrollo cultural y asistencial de la diócesis, tanto a través de la limosna, como ayudando, protegiendo y erigiendo instituciones benéfico-sociales; pues como recuerda un viajero francés, cuando enjuicia a los obispos españoles del siglo XVIII, «las rentas considerables de que gozan no las consumen en el servicio de la mesa, no teniendo más convidados que sus vicarios generales y algunos sacerdotes. La gran riqueza de los obispos no se conoce aquí sino por las continuas limosnas que reparten a los pobres $\rangle^{78}$. Esto explica que a la muerte de los obispos el espolio no fuera de gran cuantía, pues como dice el contador de la Cámara Apostólica en los reinos de España, «los gastos que contraen cuando entran en los obispados son muy crecidos, pues además de las bulas tienen que pagar la mesada que dan al rey, el coste que les causa adornarse de aquellas alhajas y decencia necesaria que debe tener un prelado, y la que ocasiona la manutención de la familia que tienen. Por ello, no debe extrañar a la Cámara que de alguno no haya recibido cosa alguna» ${ }^{79}$.

76. ASV, Arch. Nunz. Madrid, vol. 14, ff. 801-945. Memoriales de las iglesias de Castilla al Nuncio pidiendo que no se lleve a efecto el breve de Inocencio XI por el que se concede una décima de 600.000 ducados sobre las rentas del estado eclesiástico de los reinos de España a favor del emperador de Alemania. Años 1686-1687.

77. El canonista Tomás Hurtado (Resolutionum moralium (...) de congrua sustentatione ecclesiasticorum, Hispalis 1639) recuerda que el Concilio de Trento fija la congrua episcopal en mil ducados, pero añade que en España es costumbre que los obispos vivan con más esplendor. Esto hace que rehúse concretar la cantidad, si bien desciende a ciertos detalles de lo que podría constituir el ordinario de sus mesas.

78. Sempere y Guarinos, J.: Ensayo de una biblioteca de los mejores escritores del reinado de Carlos III. Madrid, Gredos, 1969, vol. I, pp. 202-203.

79. ASV, Arch. Nunz. Madrid, vol. 16, f. 446. Informe del contador de la Cámara Apostólica. Madrid 31 mayo 1706. 